\title{
Dietary Fish Oil-induced Changes in Intrahepatic Cholesterol Transport and Bile Acid Synthesis in Rats
}

Martin J. Smit, * Amo M. Temmerman, * Henk Wolters," Folkert Kuipers," Anton C. Beynen,"* and Roel J. Vonk*

${ }^{*}$ Department of Pediatrics, University of Groningen, $9712 \mathrm{KZ}$ Groningen, The Netherlands; ${ }^{\ddagger}$ Department of Laboratory Animal Science, University of Utrecht, 3508 TD Utrecht, The Netherlands; and Department of Human Nutrition,

Agricultural University, 6700 EV Wageningen, The Netherlands

\begin{abstract}
Hepatic cholesterol metabolism was studied in rats fed purified diets supplemented (9\% wt/wt) with either fish oil (FO) (n-3 fatty acids) or corn oil (CO) (n-6 fatty acids) for 4 wk. Rats were equipped with permanent catheters in heart, bile duct, and duodenum to allow studies under normal feeding conditions. $\left[{ }^{3} \mathbf{H}\right.$ cholesteryl oleate-labeled small unilamellar liposomes, which are rapidly endocytosed by hepatocytes, were intravenously injected to label intrahepatic cholesterol pools, and plasma and bile were collected. FO as compared to $\mathrm{CO}$ induced a lowering of plasma cholesterol levels by $38 \%$ and of triglyceride levels by $69 \%$. This reduction in plasma lipids in FO rats was accompanied by: ( $a$ ) an increased bile acid pool size (28\%); (b) a fourfold increase in the ratio cholic acid/chenodeoxycholic acid in bile; (c) increased biliary excretion of cholesterol (51\%); (d) accelerated excretion of endocytosed free cholesterol into bile; (e) accelerated incorporation of endocytosed cholesterol in bile acids; $(f)$ a significant increase in the bile acid-independent fraction of bile flow; and $(g)$ a threefold increase in hepatic alkaline phosphatase activity. The results show that FO induces changes in transport and metabolic pathways of cholesterol in the rat liver, which result in a more rapid disposition of plasmaderived cholesterol into the bile. (J. Clin. Invest. 1991 . 88:943951.) Key words: enterohepatic circulation • lipids • polyunsaturated fatty acids $\bullet$ corn oil $\bullet$ alkaline phosphatase
\end{abstract}

\section{Introduction}

Consumption of fish oil (FO) $)^{1}$ is associated with a reduced risk for coronary heart disease (1-4). This relation is probably of a multifactorial nature and may include changes in lipoprotein metabolism. A consistent effect of dietary FO on lipoprotein metabolism in man is a pronounced reduction in plasma triglyceride levels (5). However, plasma cholesterol is not systematically influenced by FO ingestion (see 5 for review). In a num-

Address correspondence to Martin J. Smit, Ph. D., Department of Pediatrics, Groningen University, Bloemsingel 10,9712 KZ Groningen, The Netherlands.

Received for publication 10 December 1990 and in revised form 5 April 1991.

1. Abbreviations used in this paper: ACAT, acyl-CoA:cholesterol acyltransferase; BAIF, bile acid-independent fraction of bile flow; CO, corn oil; EHC, enterohepatic circulation; FO, fish oil; HMG, 3-hydroxy-3-methylglutaryl.

J. Clin. Invest.

(c) The American Society for Clinical Investigation, Inc.

0021-9738/91/09/0943/09 \$2.00

Volume 88, September 1991, 943-951 ber of studies (6-9), in which dietary saturated triglycerides were replaced by FO, a decrease in LDL cholesterol levels was observed (5). In contrast, when FO was added as a supplement to the diet no change or even a slight increase in LDL cholesterol occurred (5). In rats, plasma cholesterol levels were greatly reduced after feeding of a diet containing FO (10-12). Recently, Ventura et al. (12) showed that this is mainly due to stimulation of hepatic lipoprotein receptor activity but the underlying mechanism remained unclear. The polyunsaturated n-3 fatty acids, eicosapentaenoic acid (C20:5 [n-3]) and docosahexaenoic acid (C22:6 [n-3]), which are present in relatively large amounts in FO, are supposed to be responsible for the observed effects of dietary FO.

Although it is recognized that the hepatobiliary pathway is the main route for removal of cholesterol from the body (13, 14), little information is available concerning dietary effects on intrahepatic cholesterol transport and bile formation. To gain further insight into the metabolic changes induced by dietary FO, we have investigated its effects on hepatic cholesterol metabolism and bile formation in the rat. The effects of purified diets containing either $9 \%(w t / w t) ~ F O$, which is rich in $n-3$ polyunsaturated fatty acids, or $9 \%$ (wt/wt) corn oil (CO), which is rich in $\mathrm{n}-6$ polyunsaturated fatty acids, were compared. Changes in plasma lipids, hepatic cholesterol metabolism, bile formation, and hepatic plasma membrane composition were determined. In addition, intravenously injected $\left[{ }^{3} \mathrm{H}\right]$ cholesteryl oleate-labeled liposomes (small unilamellar vesicles) were used as a tool to introduce labeled cholesteryl oleate into the liver. These small liposomes are known to be preferentially taken up by hepatocytes (15-17). After intralysosomal hydrolysis, the labeled cholesterol becomes available to the cell and can be used for bile acid synthesis $(16,17)$. The results show that a decrease in plasma cholesterol and triglyceride concentrations in rats fed FO is accompanied by quantitative and qualitative changes in hepatic sterol metabolism.

\section{Methods}

Materials. Tween-80, Triton WR-1339, glucose-6-phosphate, fatty acid-free BSA, oleoyl CoA, 3-hydroxy-3-methylglutaryl (HMG) CoA and mevalonic acid lactone were purchased from Sigma Chemical Co., St. Louis, MO. Glucose-6-phosphate dehydrogenase, DTT, NADP, and ATP were from Boehringer Mannheim GmbH, Mannheim, Germany. Cholesterol, $7 \alpha$-hydroxycholesterol, and $7 \beta$-hydroxycholesterol were from Steraloids, Inc., Wilton, NH. 3-Hydroxy-3-methyl[3$\left.{ }^{14} \mathrm{C}\right]$ glutaryl $\mathrm{CoA}$ and $\left[4-{ }^{14} \mathrm{C}\right]$ cholesterol were from the Radiochemical Centre, Ltd., Amersham, Bucks., UK. [5- $\left.{ }^{3} \mathrm{H}\right]-$ Mevalonic acid lactone and $\left[1-{ }^{14} \mathrm{C}\right]$ oleoyl $\mathrm{CoA}$ were obtained from New England Nuclear, Boston, MA. All other chemicals used were of analytical grade.

Liposome preparation. Small unilamellar vesicles containing a trace amount of $\left[1,2{ }^{3} \mathrm{H}\right]$ cholesteryl oleate $(48 \mathrm{Ci} / \mathrm{mmol}$; Radiochemical Centre) were made as described previously $(18,19)$. The vesicles 
were composed of cholesterol, phosphatidylcholine, and phosphatidylserine in a 5:4:1 molar ratio.

Animals. Male Wistar (Cpb:Wu) rats, aged 3 wk, were obtained from Harlan CPB, Zeist, The Netherlands. The animals were housed in groups in wire-topped polycarbonate cages with a layer of sawdust as bedding. The cages were placed in a temperature and light-controlled room (temperature $20^{\circ} \mathrm{C}$; light on between 6 a.m. and 6 p.m.). The rats were maintained on commercial rat pellets $\left(\mathrm{RMHB}^{\oplus}, \mathrm{Hope}\right.$ Farms BV, Woerden, The Netherlands). At the age of 8 wk (day 0 ), the animals were divided into two dietary groups, consisting of 18 rats each, so that the distributions of plasma cholesterol concentrations and body weights of both groups were similar. Mean plasma cholesterol concentrations and body weights on day 0 were $2.69 \mathrm{mM}$ and $264 \mathrm{~g}$, respectively. The composition of the experimental diets, which were provided in powdered form, is given in Table I. The type of fat was the only variable. The diets were balanced for cholesterol in the FO $(144 \mathrm{mg} /$ $100 \mathrm{~g}$ ). $\mathrm{CO}$ was obtained from Knorr Caterplan $\mathrm{GmbH}$, Heilbronn, FRG; FO (menhaden oil) was from Unilever Research Laboratory, Vlaardingen, The Netherlands. The animals received the experimental diets ad lib.; they had free access to tap water. From days 0 to 28, the rats were housed individually in stainless steel cages with wire mesh bases. As from day 20 on, the animals that were to be equipped with permanent catheters (see below) were housed in wire-topped polycarbonate cages with a layer of sawdust as bedding.

Table I. Composition of the Experimental Diets

\begin{tabular}{lcc}
\hline & \multicolumn{2}{c}{ Dietary oil } \\
\cline { 2 - 3 } & Corn oil & Fish oil \\
\hline Ingredients (g) & & \\
Constant components & 90 & 90 \\
Corn oil & 10 & 1 \\
Fish oil & - & 9 \\
Cholesterol & 0.08 & 0.07 \\
Chemical analysis & & \\
Cholesterol (g/100 g) & 0.08 & 0.08 \\
Crude fat (g/100 g) & 10.1 & 10.1 \\
Fatty acids (g/100 g fatty acids) & & \\
C 14:0 & nd & 6.2 \\
C 16:0 & 10.3 & 17.7 \\
C 16:1 & nd & 7.5 \\
C 18:0 & 1.9 & 3.0 \\
C 18:1 & 29.5 & 15.0 \\
C 18:2 & 55.8 & 7.6 \\
C 18:4 (n-3) & nd & 2.1 \\
C 20:1 (n-9) & 0.3 & 2.9 \\
C 20:3 (n-3) & nd & 1.0 \\
C 20:5 (n-3) & nd & 13.0 \\
C 22:1 (n-9) & nd & 2.2 \\
C 22:5 (n-3) & nd & 2.1 \\
C 22:6 (n-3) & nd & 8.4 \\
Saturated total & 12.2 & 26.9 \\
Monounsaturated total & 29.5 & 24.7 \\
Polyunsaturated (n-6) total & 55.8 & 7.6 \\
Polyunsaturated (n-3) total & & 26.6 \\
& & \\
& & \\
& & \\
& & \\
& &
\end{tabular}

The constant components consisted of (in grams): casein, 17; starch, 21; dextrose, 19; molasses, 11; cellulose, 16; dicalcium phosphate, 0.6 ; calcium carbonate, 0.7 ; magnesium carbonate, 0.07 ; magnesium oxide, 0.03 ; potassium bicarbonate, 1.9 ; sodium chloride 0.5 ; vitamin premix, 1.2; mineral premix, 1.0. The composition of the mineral and vitamin premixes have been described elsewhere (20). nd, not detectable.
Experimental procedures. On day 0 blood was collected in the nonfasting state from the orbital plexus under diethylether anesthesia. On day 21 , five rats of each group were equipped with permanent silastic catheters in bile duct, duodenum, and heart, as described earlier (21). These catheters were tunneled subcutaneously and fixed to the skull. The enterohepatic circulation (EHC) was restored immediately by connection of the bile and duodenal catheters. During bile diversion, which was started on day 30 , bile was led through a polyethylene tubing with a swivel joint, thus permitting free movement of the rats, and allowing bile formation to be studied in conscious and unrestrained animals. The heart catheter allows intracardial administration as well as repeated blood sampling without the need to handle the animals (22). Animals of both groups rapidly recovered from surgery; food intake returned to normal within 2 or $3 \mathrm{~d}$ after the operation. Experiments were started on day 30 .

On day $30,\left[{ }^{3} \mathrm{H}\right]$ cholesteryl oleate-labeled small unilamellar vesicles $\left(2 \times 10^{6} \mathrm{dpm}, 2 \mu \mathrm{mol}\right.$ lipid/100 $\mathrm{g}$ body $\left.\mathrm{wt}\right)$ were injected via the heart catheter between 11:00 and 11:15 a.m. Immediately after injection, the artificially restored EHC was interrupted and bile was collected continuously for $24 \mathrm{~h}$ in tared test tubes, by using a fraction collector. Blood samples were taken at indicated time intervals after liposome injection.

Preparation of microsomes and assay of HMG-CoA reductase, acylCoA:cholesterol acyltransferase (ACAT), and cholesterol 7 $\alpha$-hydroxylase activity. For the isolation of microsomes on days 27 and 29, four additional rats of each group were used. The animals were anesthetized with diethylether and livers were perfused in situ with ice-cold $0.25 \mathrm{M}$ sucrose until they became yellowish. Livers were immediately excised, cut into small pieces, and divided into three portions which were homogenized in different buffers (see below). All procedures were carried out at $4^{\circ} \mathrm{C}$. After centrifugation at $12,000 \mathrm{~g}$ for $20 \mathrm{~min}$, microsomes were isolated by centrifugation of the supernatant at $105,000 \mathrm{~g}$ for 60 $\mathrm{min}$. The microsomes were resuspended and washed by another centrifugation step at $105,000 \mathrm{~g}$ for $60 \mathrm{~min}$. The microsomes were resuspended (10-25 mg of microsomal protein per $\mathrm{ml}$ ), frozen in liquid nitrogen in small portions, and stored at $-60^{\circ} \mathrm{C}$ under nitrogen.

For the assay of cholesterol $7 \alpha$-hydroxylase, microsomes were isolated in a 40-mM potassium phosphate buffer, $\mathrm{pH} 7.4$, containing 100 $\mathrm{mM}$ sucrose, $50 \mathrm{mM}$ potassium fluoride, $2.0 \mathrm{mM}$ EDTA, and $5.0 \mathrm{mM}$ DTT. After the first ultracentrifugation step, the pellet was resuspended and subsequently washed and stored as described above in the same buffer without potassium fluoride and with $100 \mathrm{mM}$ potassium phosphate, $\mathrm{pH}$ 7.4. For the assay of HMG-CoA reductase, microsomes were isolated in a buffer containing $10 \mathrm{mM}$ potassium phosphate, $\mathrm{pH} 6.8$, $2.0 \mathrm{mM}$ EDTA, and $250 \mathrm{mM}$ sucrose. After the first ultracentrifugation step the pellet was resuspended and subsequently washed and stored as described above in a buffer containing $50 \mathrm{mM}$ piperazine$N, N^{\prime}$ bis(2-ethane sulfonic acid), pH $6.5,10 \mathrm{mM}$ EDTA, and $100 \mathrm{mM}$ $\mathrm{NaCl}$. For the assay of ACAT, microsomes were isolated in a buffer containing $100 \mathrm{mM}$ potassium phosphate, $\mathrm{pH} 7.4,1.0 \mathrm{mM}$ glutathione, and $10 \mathrm{mM}$ nicotinamide.

Cholesterol $7 \alpha$-hydroxylase activity was determined by measuring the synthesis of $7 \alpha$-hydroxycholesterol from $\left[{ }^{14} \mathrm{C}\right]$ cholesterol as described by Princen et al. $(23,24)$. HMG-CoA reductase was determined by measuring the conversion of $\left[{ }^{14} \mathrm{C}\right] 3$-hydroxy-3-methylglutaryl $\mathrm{CoA}$ to mevalonic acid according to Philipp and Shapiro (25). ACAT activity was determined by measuring the incorporation of $\left[{ }^{14} \mathrm{C}\right]$ oleoyl-CoA into cholesterol as described by Billheimer et al. (26).

Preparation of liver plasma membranes and enzyme assays. For the isolation of hepatic plasma membranes on day 28, eight animals per dietary group were used. The isolation method as described by Meier et al. (27) for Sprague-Dawley rats was modified for use in Wistar rats. All isolation steps were performed at $0-4^{\circ} \mathrm{C}$. Rat livers were cut into small pieces, washed in $1 \mathrm{mM} \mathrm{NaHCO}$ ( $\mathrm{pH} 7.4$ ), and homogenized and filtered. After centrifugation $(5 \mathrm{~min} 500 \mathrm{~g}+10 \mathrm{~min} 1,000 \mathrm{~g}$ ), the crude nuclear pellet was resuspended in $1 \mathrm{mM} \mathrm{NaHCO}_{3}$ and recentrifuged at $1,000 \mathrm{~g}(10 \mathrm{~min})$. The pellet was resuspended in $5.5 \mathrm{vol}$ of $56 \%$ sucrose (wt/wt) and stirred for $10 \mathrm{~min}$ to disrupt membrane aggregates. Sam- 
ples of $15 \mathrm{ml}$ of the suspension were transferred to centrifuge tubes $(40$ PA; Hitachi Ltd., Tokyo, Japan). The suspension was overlaid with 10 $\mathrm{ml} 43 \%$ sucrose, followed by $6 \mathrm{ml} 36.5 \%$ sucrose. The tubes were filled to the top with $0.25 \mathrm{M}$ sucrose and centrifuged for $120 \mathrm{~min}$ at 22,000 $\operatorname{rpm}(65,000 \mathrm{~g})$ in a swing-out rotor (type SRP 28) in an ultracentrifuge (2331; LKB Instruments, Inc., Bromma, Sweden). The plasma membranes were recovered from the $36.5-43 \%$ interface and washed as described (27). The accuracy of the isolation procedure was checked by determining the activity of a number of plasma membrane marker enzymes. $\mathrm{Na}^{+} \mathrm{K}^{+}$-ATPase and $\mathrm{Mg}^{2+}$-ATPase were determined by the kinetic assay described by Scharschmidt et al. (28), leucine aminopeptidase by the method of Goldbarg and Rutenberg (29), and alkaline phosphatase according to Keeffe et al. (30). As a test for the presence of intracellular organelles were determined: glucose-6-phosphatase for endoplasmic reticulum (31); succinate cytochrome c reductase for mitochondria (32); and acid phosphatase for lysosomes (33). Fluorescence depolarization of diphenylhexatriene, which gives an indication of membrane fluidity, was determined as described previously (34).

Analyses. Biliary bile acid concentration was determined by an enzymatic fluorimetric assay (Sterognost-Flu; Nyegaard Co., Oslo, Norway). Bile acid composition was analyzed by capillary gas chromatography and gas chromatography-mass spectrometry (GC-MS) as described previously (17). Analysis of radioactive bile acids was performed as described by Princen and Meijer (35). Cholesterol and phospholipids in bile were measured after lipid extraction (36), according to the methods of Gamble et al. (37) and Böttcher et al. (38), respectively. The mass of cholesterol and cholesteryl ester in liver was determined after lipid extraction (36) by a method using cholesterol oxidase, cholesterol esterase, and peroxidase (CHOD-PAP kit, catalogue no. 310328; Boehringer Mannheim). The same kit was used to determine plasma cholesterol concentrations. Triglyceride concentrations were determined enzymatically as described (39). Protein was determined according to Lowry et al. (40) with BSA as a standard.

For measurement of radioactivity, bile and liver homogenate samples were decolorized with an equal volume of $30 \%$ hydrogen peroxide, before administration of the scintillant (Hydroluma; J. T. Baker, Deventer, The Netherlands). Plasma samples were counted after addition of Plasmasol (Packard Instrument Company, Downers Grove, IL). Radioactivity was determined in a liquid scintillation counter (LKB Instruments) equipped with an external standard to correct for quenching.

Calculations and statistics. Values are presented as means \pm SEM. Significance of differences between dietary groups was assessed by Student's $t$ test, at a $P<0.05$ level of significance.

\section{Results}

Body weights, feed intake, and plasma lipids. The type of fat in the diets did not influence food intake and weight gain of the rats. The mean intake of food was 22.5 and $23.1 \mathrm{~g} / \mathrm{d}$ in the $\mathrm{CO}$ and FO groups, respectively. The mean increase in body weight was 3.2 and $3.4 \mathrm{~g} / \mathrm{d}$ in the $\mathrm{CO}$ and $\mathrm{FO}$ groups, respectively.

After 4 wk of feeding the FO diet, plasma cholesterol concentrations were on average reduced by $33 \%$ and triglyceride concentrations by $68 \%$ (Fig. 1). No significant effects with time on plasma cholesterol and triglyceride concentrations were observed after $\mathrm{CO}$ feeding.

Biliary excretion. Bile was collected in 1-h intervals during $4 \mathrm{~h}$ immediately after interruption of the EHC, and in two subsequent 10 -h intervals. In the FO group, the amount of bile acids excreted during the first $4 \mathrm{~h}$ was increased by $28 \%$ compared to the $\mathrm{CO}$ group, indicating that dietary FO increases bile acid pool size (Table II). Bile flow in rats fed FO was increased by $37 \%$, and cholesterol output by $51 \%$. Phospholipid excretion was increased by $58 \%$, but the difference did not reach

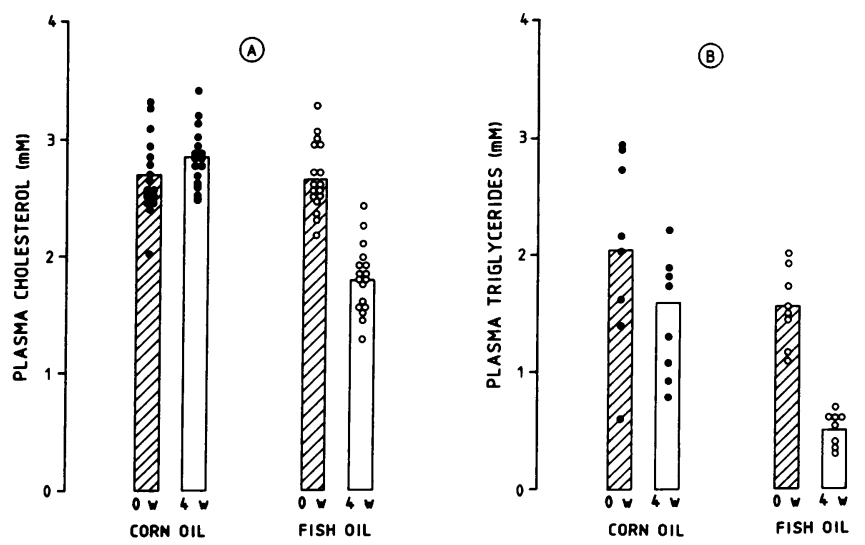

Figure 1. Plasma cholesterol $(A)$ and triglyceride concentrations $(B)$ of rats at the start of the experiment $(0 \mathrm{w})$ and after 4 weeks $(4 \mathrm{w})$ on a diet containing either $9 \% \mathrm{CO}(\bullet)$ or FO (0). Cross-hatched bars indicate group means at the start of the experiment. The clear bars indicate group means after $4 \mathrm{wk}$ on the diet. Circles indicate individual values. Cholesterol concentration was determined in plasma samples of 16 and 17 animals of the $\mathrm{CO}$ and FO groups, respectively. Triglyceride concentrations were determined in eight plasma samples of each group.

statistical significance due to large interindividual variations. In the rat model employed, exhaustion of the endogenous bile acid pool occurs within $4 \mathrm{~h}(21,41)$. Output of bile acids in the subsequent period therefore represents hepatic de novo synthesis. Time courses of bile flow and output rates of bile acids, phospholipids, and cholesterol are shown in Fig. 2. After exhaustion of the pool, no significant differences in output of bile acids, biliary phospholipids, and biliary cholesterol were observed between the groups, although output of all three bile constituents tended to be lower in rats fed FO (Table II). In contrast, bile flow was higher in these rats during the complete course of the experiment. Regression analysis of bile flow and bile acid output during the first $4 \mathrm{~h}$ after interruption, as first described by Berthelot et al. (42), revealed that the higher bile flow in rats fed FO was due to a significant $(P<0.05)$ increase in the so-called bile acid-independent fraction of bile flow (BAIF), which was $2.23 \mathrm{ml} / \mathrm{kg}$ per $\mathrm{h}$ in these animals compared

Table II. Bile Flow and Biliary Excretion of Bile Acids, Phospholipids, and Cholesterol during 0-4 $h$ and 4-24 $h$ after Interruption of the Enterohepatic Circulation

\begin{tabular}{lcccc}
\hline $\begin{array}{c}\text { Interval, } \\
\text { dietary oil }\end{array}$ & Bile flow & Bile acids & Phospholipids & Cholesterol \\
\hline & $m l / k g$ & $\mu m o l / k g$ & $\mu m o l / k g$ & $\mu m o l / k g$ \\
& & & & \\
0-4 h & & & & \\
Corn oil & $9.16 \pm 0.56$ & $303 \pm 8$ & $31.6 \pm 5.9$ & $2.93 \pm 0.39$ \\
$\begin{array}{l}\text { Fish oil } \\
\text { 4-24 h }\end{array}$ & $12.57 \pm 0.95^{*}$ & $388 \pm 32^{*}$ & $49.9 \pm 7.8$ & $4.42 \pm 0.32^{*}$ \\
Corn oil & $29.88 \pm 1.29$ & $288 \pm 21$ & $74.6 \pm 12.0$ & $10.01 \pm 0.76$ \\
Fish oil & $37.80 \pm 1.37^{*}$ & $233 \pm 30$ & $54.7 \pm 9.2$ & $8.35 \pm 0.97$ \\
& & & &
\end{tabular}

Two groups of animals were fed diets containing either $\mathrm{CO}$ or FO for $4 \mathrm{wk}$. Each value represents the mean \pm SEM for data obtained in five animals. * The values are significantly different at the $P<0.05$ level from the corresponding values in the corn oil group. 

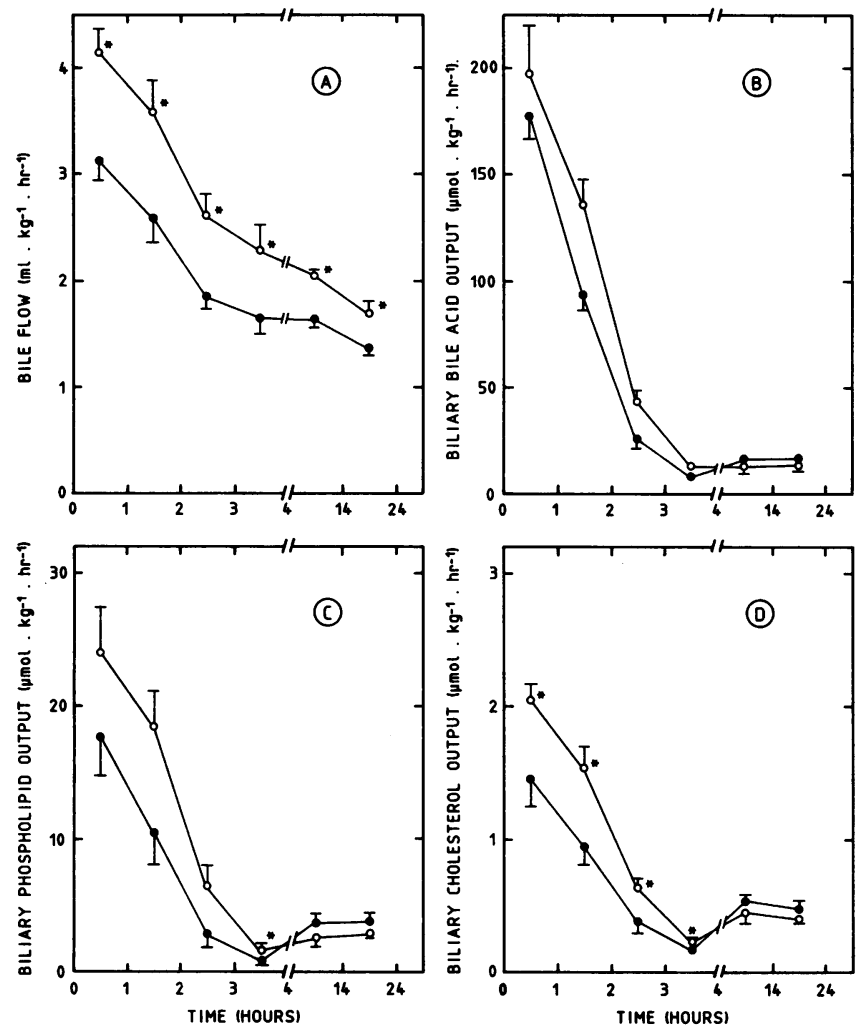

Figure 2. Bile flow $(A)$ and excretion of bile acids $(B)$, phospholipids $(C)$, and cholesterol $(D)$ during $24 \mathrm{~h}$ after interruption of the enterohepatic circulation of rats fed CO ( $(\bullet)$ or FO (o) for 4 wk. Data represent means \pm SEM for five animals. *Significant difference $(P<0.05)$.

to $1.61 \mathrm{ml} / \mathrm{kg}$ per $\mathrm{h}$ in rats fed $\mathrm{CO}$ (Fig. 3). In both groups the bile acid-dependent bile flow was similar; i.e., $9.38 \mu \mathrm{l} / \mu \mathrm{mol}$ in the FO group and $8.96 \mu \mathrm{l} / \mu \mathrm{mol}$ in the $\mathrm{CO}$ group.

Effects of FO on bile acid pool composition and synthesis of individual bile acid species. The composition of the bile acid pool and of newly synthesized bile acids was determined by gas chromatography and gas chromatography-mass spectrometry in bile samples in the period 0-2 $\mathrm{h}$ and 21-24 $\mathrm{h}$ after interruption of the EHC, respectively. This analysis revealed a signifi- cant difference between the two dietary groups (Table III). The pool of FO rats contained relatively more cholic acid and less chenodeoxycholic acid and muricholic acids. This difference was caused by altered hepatic synthesis rates of the latter bile acid species, as synthesis of chenodeoxycholic acid was markedly depressed in rats fed FO (Table III). The bile acid pool of both groups of rats contained a considerable amount, i.e., up to $20 \%$, of a tertiary bile acid, which was tentatively identified as $3 \alpha, 6 \alpha, 7 \beta, 12 \alpha$-tetrahydroxy- $5 \beta$-cholanoic acid as based on its GC-MS spectrum (43). As this bile acid was found in much smaller amounts, i.e., $\sim 4 \%$ in rats fed normal chow, it is tempting to speculate that the use of purified diet induces changes in bile acid metabolism.

Hepatic cholesterol, enzyme activities, and plasma membranes. No differences between rats fed FO or $\mathrm{CO}$ were observed in the amount of free and esterified cholesterol in the liver (Table IV). The increased bile acid pool size in rats fed FO was apparently not caused by an increase in hepatic bile acid synthesis (see also Fig. 2): the activity of microsomal cholesterol $7 \alpha$-hydroxylase, the rate-limiting enzyme in bile acid synthesis, was not altered by FO feeding (Table IV). The group mean activities of microsomal ACAT and HMG-CoA reductase, the rate-limiting enzymes in cholesterol esterification and cholesterol synthesis, respectively, were decreased in rats fed FO but the lowering failed to reach statistical significance.

No dietary effects were observed as to the relative amounts of phospholipids and cholesterol in total hepatic plasma membranes, or in membrane fluidity (Table V). No attempts were made to differentiate between sinusoidal and canalicular membrane fractions in this study. FO treatment induced an almost threefold increase in hepatic alkaline phosphatase activity. Activities of the other plasma membrane enzymes were not differentially influenced by dietary FO and $\mathrm{CO}$.

Hepatic processing of liposome-derived $\left[{ }^{3} \mathrm{H}\right]$ cholesteryl oleate. To gain insight into the effects of dietary fat on hepatic handling of endocytosed cholesteryl ester, rats of both dietary groups were intravenously injected with small unilamellar liposomes labeled with $\left[{ }^{3} \mathrm{H}\right]$ cholesteryl oleate. By using liposomes as vehicle for cholesteryl oleate, we bypassed potential effects of the diet on receptor-mediated uptake processes, as recently described for LDL particles in FO-treated rats (12). No dietary effects were observed on plasma elimination of the liposomes

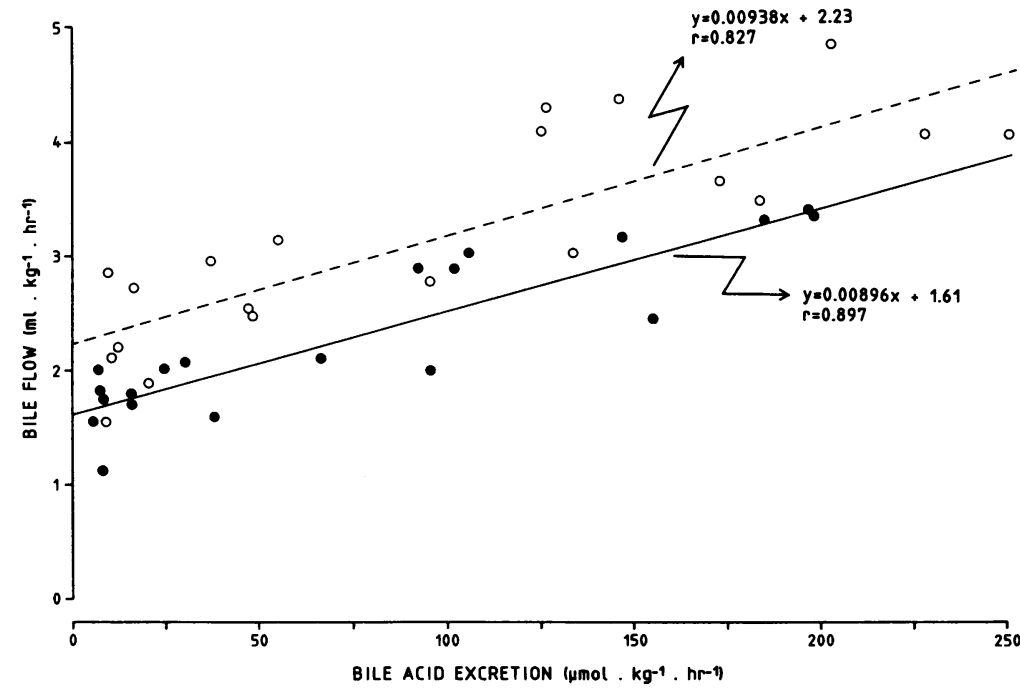

Figure 3. Relation between bile flow and biliary bile acid excretion measured in 1-h intervals during the first $4 \mathrm{~h}$ after interruption of the enterohepatic circulation of rats fed either with $\mathrm{CO}(\bullet)(n=5)$ or $\mathrm{FO}(0)(n=5)$ for 4 wk. Regression analysis was carried out as first described by Berthelot et al. (42). 


\begin{tabular}{|c|c|c|c|c|}
\hline & \multicolumn{2}{|c|}{ Bile acid pool } & \multicolumn{2}{|c|}{ Bile acid synthesis } \\
\hline & \multicolumn{2}{|c|}{$\%$ of total bile acids } & \multicolumn{2}{|c|}{$\%$ of total bile acids } \\
\hline & Corn oil & Fish oil & Corn oil & Fish oil \\
\hline Cholic acid & $42.8 \pm 2.9$ & $57.5 \pm 2.6^{*}$ & $57.3 \pm 2.3$ & $76.4 \pm 1.5^{*}$ \\
\hline Chenodeoxycholic acid & $4.2 \pm 0.3$ & $1.3 \pm 0.1^{*}$ & $24.6 \pm 2.8$ & $8.1 \pm 1.0^{*}$ \\
\hline$\beta$ Muricholic acid & $10.5 \pm 3.8$ & $5.8 \pm 1.6$ & $12.9 \pm 1.0$ & $11.0 \pm 0.8$ \\
\hline$\alpha$ Muricholic acid & $2.7 \pm 0.6$ & $0.9 \pm 0.2^{*}$ & nd & nd \\
\hline Ursodeoxycholic acid & $1.5 \pm 0.4$ & $0.6 \pm 0.0$ & $1.9 \pm 0.1$ & $1.1 \pm 0.1^{*}$ \\
\hline Hyocholic acid & $0.3 \pm 0.0$ & $0.5 \pm 0.0^{*}$ & $0.5 \pm 0.1$ & $0.8 \pm 0.1$ \\
\hline $3 \alpha, 6 \alpha, 7 \beta, 12 \alpha$-Tetrahydroxy-5 $\beta$-cholanoic acid & $22.3 \pm 4.3$ & $20.7 \pm 2.9$ & $0.3 \pm 0.2$ & $0.3 \pm 0.1$ \\
\hline Hyodeoxycholic acid & $5.5 \pm 0.3$ & $3.4 \pm 0.6^{*}$ & $0.8 \pm 0.6$ & $0.8 \pm 0.3$ \\
\hline$\omega$ Muricholic acid & $1.7 \pm 0.3$ & $2.3 \pm 0.5$ & $0.1 \pm 0.1$ & $0.1 \pm 0.1$ \\
\hline Deoxycholic acid & $1.2 \pm 0.3$ & $1.8 \pm 0.4$ & $0.5 \pm 0.3$ & $0.4 \pm 0.3$ \\
\hline Unidentified & $7.4 \pm 0.9$ & $6.2 \pm 0.4$ & $0.6 \pm 0.2$ & $1.0 \pm 0.1$ \\
\hline
\end{tabular}

Two groups of animals were fed diets containing either CO or FO for 4 wk. Each value represents the mean \pm SEM for data obtained in five animals. Bile acid pool composition was measured in bile obtained during a period of $2 \mathrm{~h}$ immediately after interruption of the EHC. The absolute amounts of bile acids in the pool were $303 \pm 8$ and $388 \pm 32 \mu \mathrm{mol} / \mathrm{kg}$ for the $\mathrm{CO}$ and FO group, respectively. Bile acid synthesis was measured in bile obtained during the period of 21-24 h after interruption of the EHC. The absolute amounts of bile acids synthesized during this period were $32.7 \pm 3.0$ and $30.3 \pm 2.4 \mu \mathrm{mol} / \mathrm{kg}$ in the $\mathrm{CO}$ and FO group, respectively. ${ }^{*}$ The values are significantly different at the $P<0.05$ level from the corresponding values in the corn oil group.

(Fig. 4), indicating that the amount of labeled liposomes taken up by the liver was similar in the two experimental groups.

Biliary excretion of radioactivity occurred more rapidly in rats fed FO as compared to CO (Fig. 5). During the first $4 \mathrm{~h}$ after interruption of the EHC, output of radioactivity in the form of cholesterol was increased by $58 \%$ in rats fed FO. As described above, this effect was accompanied by a similar increase in biliary output of cholesterol mass. An increased incorporation of liposome-derived radioactivity into bile acids was also observed $(+32 \%)$, at least during the initial 4-h period in which bile acids are drained from the pool (Fig. 5). After exhaustion of the bile acid pool, no significant differences were observed in biliary excretion of labeled bile constituents. The specific activities of bile acids and cholesterol of both dietary groups were similar (Fig. 6). The difference between the dietary groups in mass synthesis of individual bile acid species (see

Table IV. Hepatic Cholesterol Content and Microsomal Enzyme Activities

\begin{tabular}{|c|c|c|}
\hline & \multicolumn{2}{|c|}{ Dietary oil } \\
\hline & Corn oil & Fish oil \\
\hline \multicolumn{3}{|l|}{ Cholesterol (nmol/mg protein) } \\
\hline Free & $25.81 \pm 0.76(10)$ & $27.11 \pm 4.55(11)$ \\
\hline Esterified & $12.86 \pm 1.60(10)$ & $12.65 \pm 6.60(11)$ \\
\hline \multicolumn{3}{|l|}{$\begin{array}{l}\text { Enzymes (pmol/min per } m g \\
\text { protein) }\end{array}$} \\
\hline ACAT & $766 \pm 130$ & $567 \pm 91$ \\
\hline HMG-CoA reductase & $41 \pm 8$ & $30 \pm 10$ \\
\hline Cholesterol $7 \alpha$-hydroxylase & $3.8 \pm 0.6 \quad(3)$ & $3.9 \pm 0.4$ \\
\hline
\end{tabular}

Two groups of animals were fed diets enriched with $\mathrm{CO}$ or FO for 4 wk. Each value represents the mean \pm SEM. Number of animals in parentheses.
Table III) was also observed in the incorporation of the liposome-derived $\left[{ }^{3} \mathrm{H}\right]$ cholesteryl ester into bile acids (Table VI): relatively more radioactivity was secreted in the form of cholic and less in chenodeoxycholic acid in FO-fed rats.

\section{Discussion}

This study shows that dietary FO as compared to CO induces a number of changes in hepatic cholesterol and bile acid metabolism in rats and provides important new information concerning the mechanism by which dietary $n-3$ fatty acids influence hepatic sterol metabolism. The decrease in plasma triglyceride concentrations after FO feeding was the most pronounced effect on plasma lipids, confirming results of other studies (1012). A number of investigators have shown that $F O$ reduces VLDL secretion by the liver in both humans and experimental animals (44-46), which explains the observed decrease in plasma triglyceride concentrations. The reduction in hepatic VLDL synthesis and secretion in turn, has been shown to be related to inhibition of hepatic triglyceride synthesis by $n-3$ fatty acids (45, 47-51). Apart from plasma triglyceride concentrations, dietary FO also lowers plasma cholesterol in the rat $(10,12)$. Recently, Ventura et al. (12) analyzed the effects of FO on plasma lipids of rats in detail. These workers compared n-3 fatty acids (FO) with n-6 fatty acids (safflower oil) and found a $38 \%$ decrease in plasma cholesterol concentrations with n-3 fatty acids. The lowering occurred mainly in the VLDL, LDL, and apoprotein E-containing $\mathrm{HDL}_{1}$ particles, i.e., $\mathrm{d}<1.095$ $\mathrm{g} / \mathrm{ml}$ density fractions. It was shown that this effect of FO was mainly due to a relatively high LDL receptor activity in the liver, in combination with a low LDL production rate.

Hepatic lipoprotein metabolism and bile acid synthesis are known to be connected by complex intrahepatic pathways (13, 14). Increased intake of cholesterol results in increased bile acid synthesis in the rat. Changes in the size of the bile acid pool have been shown to influence LDL receptor activity and LDL 
Table V. Characterization and Fluidity of Plasma Membranes

\begin{tabular}{|c|c|c|}
\hline & \multicolumn{2}{|c|}{ Dietary oil } \\
\hline & Corn oil & Fish oil \\
\hline Marker enzymes & \multicolumn{2}{|c|}{$\begin{array}{c}\text { Homogenate } \\
\text { (specific activity) }\end{array}$} \\
\hline Glucose-6-phosphatase & $4.38 \pm 0.44$ & $4.74 \pm 0.48$ \\
\hline Succinaat cyt. c reductase & $2.38 \pm 0.19$ & $2.43 \pm 0.18$ \\
\hline Leucine aminopeptidase & $0.46 \pm 0.05$ & $0.48 \pm 0.04$ \\
\hline Alkaline phosphatase & $0.13 \pm 0.05$ & $0.36 \pm 0.11^{*}$ \\
\hline $\mathrm{Mg}^{2+}$ ATPase & $2.49 \pm 0.19$ & $2.72 \pm 0.18$ \\
\hline \multirow[t]{2}{*}{$\mathrm{Na}^{+} \mathrm{K}^{+}$ATPase } & $1.13 \pm 0.28$ & $1.16 \pm 0.25$ \\
\hline & \multicolumn{2}{|c|}{$\begin{array}{l}\text { Plasma membranes } \\
\text { (relative enrichment) }\end{array}$} \\
\hline Glucose-6-phosphatase & $1.07 \pm 0.26$ & $0.85 \pm 0.27$ \\
\hline Succinaat cyt. c reductase & $1.72 \pm 0.29$ & $1.40 \pm 0.33$ \\
\hline Leucine aminopeptidase & $1.94 \pm 0.24$ & $3.53 \pm 1.47$ \\
\hline Alkaline phosphatase & $3.9 \pm 0.9$ & $4.2 \pm 0.4$ \\
\hline $\mathrm{Mg}^{2+}$ ATPase & $7.2 \pm 1.6$ & $9.1 \pm 2.4$ \\
\hline $\mathrm{Na}^{+} \mathrm{K}^{+}$ATPase & $5.9 \pm 3.0$ & $6.0 \pm 1.2$ \\
\hline ATPases (mean) & $6.8 \pm 1.8$ & $8.2 \pm 1.8$ \\
\hline
\end{tabular}

Fluidity

Total membranes

$0.149 \pm 0.009$

$0.157 \pm 0.021$

Plasma membranes

$0.176 \pm 0.013$

$0.199 \pm 0.025$

Lipids in plasma membranes

Cholesterol

$0.093 \pm 0.015$

$0.103 \pm 0.026$

Phospholipids

$0.227 \pm 0.016$

$0.262 \pm 0.021$

Data are given as means \pm SEM of four preparations from eight livers (for each preparation two livers were combined). Specific activities of enzymes are expressed as $\mu \mathrm{mol}$ product formed $\cdot \mathrm{mg}_{\text {protein }}{ }^{-1} \cdot \mathrm{h}^{-1}$. The fluidity is measured as the degree of fluorescence polarization of diphenylhexatriene. Cholesterol and phospholipid concentrations are expressed as $\mu \mathrm{mol} \cdot \mathrm{mg}$ protein ${ }^{-1}$. ${ }^{*}$ Significantly different at $P<0.05$ from the corresponding value in the $\mathrm{CO}$ group. Relative enrichment is defined as the ratio of specific activity in the plasma membranes to specific activity in the homogenate.

production rates in the hamster, but the response in rats seems to be different; feeding of bile acids to rats did not affect hepatic LDL transport and plasma LDL cholesterol concentrations (52). It is known that the influx of lipoprotein cholesterol influences bile acid synthesis; recently, Junker and Davis (53) showed in isolated rat hepatocytes that receptor-mediated uptake of LDL increased bile acids synthesis, whereas receptor-independent uptake did not. The mechanism by which dietary FO enhances hepatic LDL receptor activity is not known. This effect may be mediated by a change in cholesterol balance across the liver, by a change in lipid environment of the receptor in the sinusoidal membrane, or by a change in compartmentation of cholesterol in the liver. In contrast to the situation in man, plasma cholesterol concentrations in the rat usually do not respond to changes in hepatic cholesterol balance, which makes the first option unlikely. For example, interruption of the EHC or feeding cholestyramine does not lead

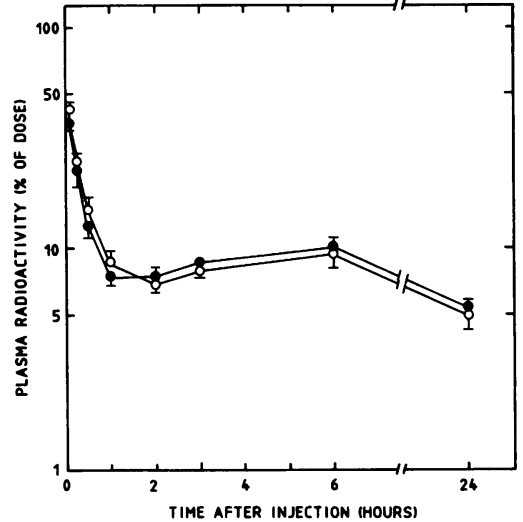

Figure 4. Elimination from plasma of intravenously injected liposomes in rats fed $\mathrm{CO}$ (•) or FO (o) for 4 wk. Data represent means \pm SEM for five animals.

to higher hepatic receptor activity and consistently lower plasma cholesterol levels in this species $(21,41,54)$. Our results suggest that FO does not induce gross changes in hepatic cholesterol balance, as we observed no change in cholesterol synthesis and bile acid synthesis. We found a $51 \%$ increase in biliary output of cholesterol (increase of $0.7 \mu \mathrm{mol} / \mathrm{kg}$ per h), but biliary output of cholesterol is relatively small in rats and can easily be compensated by a small decrease in bile acid synthesis (synthesis $= \pm 12 \mu \mathrm{mol} / \mathrm{kg}$ per $\mathrm{h}$ ). In addition, our results obtained with hepatic plasma membranes do not support the second possibility. In agreement with this, Ventura et al. found no dietary effects on receptor-mediated endocytosis of asialoglycoproteins (12). Our results, however, provide evidence for diet-induced changes in compartmentation of cholesterol in the liver.

We observed a $28 \%$ increase in bile acid pool size after FO feeding which was not due to an increased bile acid synthesis, as can be concluded from the in vivo bile acid production rates and the in vitro activity of cholesterol $7 \alpha$-hydroxylase in isolated liver microsomes. The increased bile acid pool size in combination with an unaffected rate of de novo synthesis of bile acids suggests that intestinal absorption of the bile acids was more efficient in the FO-fed animals. The increase in pool size apparently did not result in a more effective feedback inhibition of bile acid synthesis although bile acid synthesis tended to be lower in the animals fed FO. These phenomena were accompanied by a considerable increase in the cholic acid/
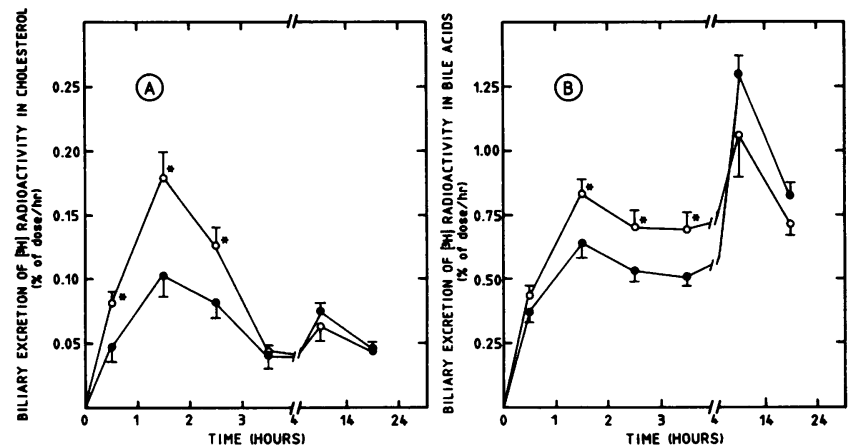

Figure 5. Biliary excretion of $\left[{ }^{3} \mathrm{H}\right]$ radioactivity in cholesterol $(A)$ and bile acids $(B)$ after intravenous administration of $\left[{ }^{3} \mathrm{H}\right]$ cholesteryl oleate-containing liposomes to rats fed $\mathrm{CO}(\bullet)$ or FO (O) for $4 \mathrm{wk}$. Data represent means \pm SEM for five animals. *Significant difference $(P<0.05)$. 


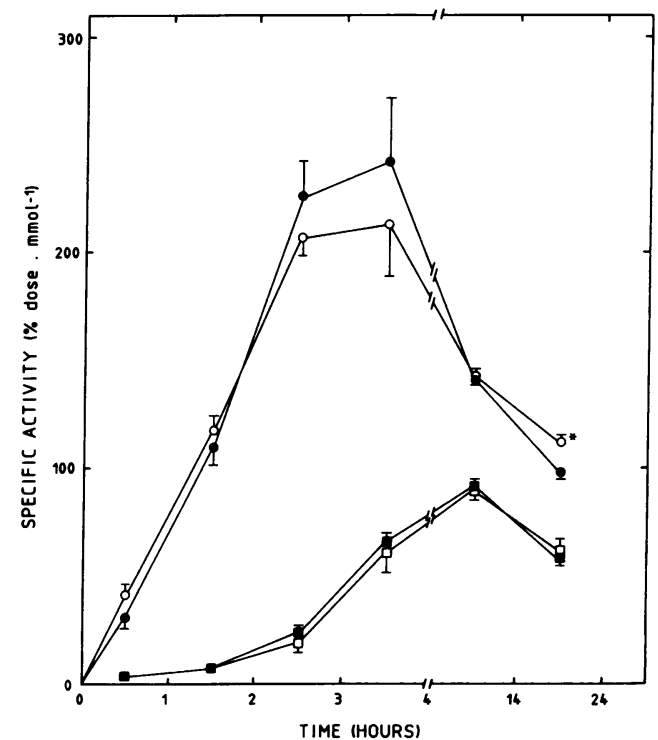

Figure 6. Specific radioactivity of biliary cholesterol $(\bullet, 0)$ and bile acids $(\square, \square)$ in rats fed CO (closed symbols) or FO (open symbols) for 4 wk. Data represent means \pm SEM for five animals. *Significant difference $(P<0.05)$.

chenodeoxycholic acid ratio in the FO group, due to a diminished chenodeoxycholic acid synthesis. This effect was observed both in mass synthesis and in synthesis from a tracer of radiolabeled cholesterol (Tables III and VI). This difference in bile acid pool composition may account for the apparently less efficient feedback inhibition of cholesterol $7 \alpha$-hydroxylase. More hydrophobic bile acids have been reported to be the most potent inhibitors (55-57). However, the intestines may also play a regulatory role in the EHC of bile salts as has recently been shown by Lilienau et al. (58). In rats, as in man, cholic acid is quantitatively the major bile acid synthesized in the liver. The observed change in cholic acid/chenodeoxycholic acid ratio suggests an effect of dietary FO on the regulation of the synthesis of the two primary bile acids in the liver. The molecular mechanism of this regulation is not fully understood, but it has been suggested that in rats the activity of the microsomal $12 \alpha$-hydroxylase system plays a pivotal role or, alternatively, the activity of this enzyme relative to that of the microsomal and/or mitochondrial 26-hydroxylase (59). A lack

Table VI. Synthesis of $\left.{ }^{\beta} H\right]$-labeled Bile Acids

\begin{tabular}{lcc}
\hline & \multicolumn{2}{c}{$\left[{ }^{3} \mathrm{H}\right]$-labeled bile acids $(\%$ of total) } \\
\cline { 2 - 3 } \multicolumn{1}{c}{ Bile acids } & Corn oil & Fish oil \\
\hline Cholic acid & $55 \pm 3$ & $77 \pm 2^{*}$ \\
$\beta$ Muricholic acid & $13 \pm 1$ & $11 \pm 1$ \\
Chenodeoxycholic acid & $27 \pm 2$ & $8 \pm 1^{*}$ \\
Polar bile acids & $5 \pm 1$ & $4 \pm 2$
\end{tabular}

Two groups of animals were fed diets enriched with corn oil or fish oil for $4 \mathrm{wk}$. Each value represents the mean \pm SEM for data obtained in five animals. Synthesis of labeled bile acids was measured in bile obtained during the period of 21-24 h after interruption of the EHC.

* The values are significantly different at the $P<0.05$ level from the corresponding values in the corn oil group. of regulatory importance of $12 \alpha$-hydroxylase in man was demonstrated by Björkhem (60). Whether FO induces changes in activities of the enzymes involved in bile acid synthesis is currently under investigation. In a number of other conditions changes in cholic acid/chenodeoxycholic acid ratio have been described. A patient with fish-eye disease, with high density lipoprotein levels less than $10 \%$ of normal, showed a reduced cholic acid/chenodeoxycholic acid ratio (61). Patients with alcoholic cirrhosis have a reduced cholic acid synthesis (62) and the thyroid hormone status has been shown to affect the cholic acid/chenodeoxycholic acid ratio in rats (63). It may be that the observed effects of FO on cholic and chenodeoxycholic acid synthesis reflect differences in the use of cholesterol from different precursor pools. Stange et al. (64) showed that in rats chenodeoxycholic acid is predominantly synthesized from preexisting cholesterol, whereas relatively more newly synthesized cholesterol is used for cholic acid synthesis. However, we found very similar changes in mass synthesis and synthesis from liposome-derived cholesterol, indicating no preferential incorporation of this preexisting cholesterol in any of the bile acid species.

Despite similar rates of total bile acid synthesis in both experimental groups, the incorporation of liposome-derived labeled cholesterol into bile acids was higher $(+30 \%)$ in the FO group during the first period after interruption. In this period bile acids are drained from the endogenous pool, resembling the natural "intact" situation in which large amounts of bile acids continuously pass through the liver. The results suggest that the higher flow of bile acids through the liver in the FO group somehow induces a shift of endocytosed liposome-derived cholesterol to the microsomal compartment for bile acid synthesis. In our study a $28 \%$ increase in bile acid transport resulted in a proportional $30 \%$ increase in microsomal incorporation of labeled cholesterol into bile acids. In agreement with this explanation is the observation that the increased incorporation of label in bile acids had disappeared after exhaustion of the bile acid pool. In this period the synthesis of bile acids from labeled cholesterol tended to be lower in the FO group, which is in line with the tendency towards lower hepatic bile acid synthesis rates. As a result, no difference in specific activity of the bile acids was observed between both dietary groups. From the present results, it cannot be determined whether the induced shift in cholesterol transport to the microsomal compartment is typical for an FO diet or represents a nonspecific secondary effect of the increased transport and processing of bile acids from the sinusoidal to the canalicular site of the liver.

We observed no significant differences between the dietary groups in hepatic cholesterol synthesis (HMG-CoA reductase activity), cholesterol esterification (ACAT activity), and in the amounts of free and esterified cholesterol in the liver. A decrease in hepatic cholesterol synthesis by dietary FO in comparison with $n-6$ polyunsaturated fatty acids has been observed by Topping et al. (65), whereas we and others observed no difference (this study, 12). This provides evidence again that cholesterol synthesis does not play a major regulatory role in determining plasma cholesterol levels in rats fed FO.

In our study, biliary excretion of cholesterol was increased by $51 \%$ in the FO group during the first period after interruption of the EHC in concert with the higher output of bile acids. The lithogenic index of bile was slightly higher in the FO group as compared to the $\mathrm{CO}$ group, but the difference was not signifcant. Biliary output of labeled cholesterol was increased by $58 \%$ 
in the FO group. The resulting similar specific activities between both dietary groups indicates that the liposome-derived cholesterol was diluted to the same extent in intracellular pools destined for biliary excretion. Our results differ from those reported by Balasubramaniam et al. (10) who found no change in the amount of bile acids excreted and a fivefold increase in cholesterol excretion in rats fed FO. These investigators used much younger rats which might explain the different results.

In addition to the changes in hepatic cholesterol and bile acid metabolism, dietary FO induced increases in hepatic alkaline phosphatase activity and the BAIF. The BAIF was increased to $2.23 \mathrm{ml} / \mathrm{kg}$ per $\mathrm{h}$ in rats fed FO. In previous studies (66) we determined a value of $1.61 \mathrm{ml} / \mathrm{kg}$ per $\mathrm{h}$ in rats fed lab chow, which is similar to the value observed in the $\mathrm{CO}$ group. It has been proposed that the BAIF is to a large extent determined by excretion of glutathione (67). However, glutathione is probably not involved in the FO-induced increase in BAIF, since we did not find an increased biliary excretion of glutathione (results not shown). Also, no differences were observed in membrane cholesterol, phospholipids, fluidity, and NaK-ATPase activities, which suggests that these parameters are not involved in the observed diet-induced change in bile flow (68). Hepatic alkaline phosphatase activity was threefold increased in the FO group. This is compatible with results of Stenson et al. (69), who observed an increase in alkaline phosphatase activity in the small intestine of rats after feeding a FO diet. The authors suggested that changes in the local lipid environment of the enzyme caused the observed increase in activity. Brasitus et al. (70) concluded that in the small intestinal microvillus membrane the cholesterol/phospholipid molar ratio rather than total membrane fluidity affects alkaline phosphatase activity: a decrease of this ratio was associated with increased enzyme activity. In our experiments, however, no differences in cholesterol/phospholipid content were found, although of course local lipid microenvironments may have been changed in response to the different diets, thus modifying alkaline phosphatase activity. Our data on hepatic alkaline phosphatase are in perfect agreement with those recently reported by Ogawa et al. (71), who showed that an increased bile acid flux through the liver stimulates alkaline phosphatase activity, especially bile acids containing a $12 \alpha$-hydroxyl group. Hence, the high hepatic activity of alkaline phosphatase in the FO rats is probably related to the increased flux of bile acids, especially that of cholic acid.

This study demonstrates that, in the rat, concomitant with the well-known FO-induced decrease in plasma cholesterol and triglyceride levels, a number of changes in hepatic cholesterol metabolism occur. Overall hepatic sterol fluxes were altered by an increased bile acid transport through the liver and a higher biliary excretion of cholesterol. Indicators of FO-induced shifts in intrahepatic pathways of cholesterol were the qualitative change in bile acid synthesis and preferential use of liposome-derived endocytosed cholesterol for bile acid synthesis. These effects were accompanied by an increase in BAIF and alkaline phosphatase activity, but not by changes in total hepatic cholesterol content, cholesterol synthesis or esterification, and total bile acid synthesis. The ultimate result was a more rapid disposition of endocytosed cholesterol into the bile. Whether there is a relation between these events and the regulation of hepatic lipoprotein receptor activity and lipoprotein synthesis remains to be established.

\section{Acknowledgments}

The authors thank Henriette Morsselt for preparing the liposomes, Bert Wolthers for GC-MS, Rick Havinga and Albert Gerding for technical and analytical support, and Lodewijk Martijn for drawing the figures.

This study was supported by grant 86-067 from the Dutch Heart Foundation. Henk Wolters was supported by a grant from the Netherlands Digestive Diseases Foundation. Folkert Kuipers is a Research Fellow of the Royal Netherlands Academy of Arts and Sciences.

\section{References}

1. Dyerberg, J., and M. O. Bang. 1982. A hypothesis on the development of acute myocardial infarction in Greenlander. Scand. J. Clin. Lab. Invest. 42(Suppl. 161):7-13.

2. Kromann, N., and A. Green. 1980. Epidemiological studies in the Upernavik District, Greenland. Acta Med. Scand. 208:401-406.

3. Kromhout, D., E. B. Bosschieter, and C. de Lezenne Coulander. 1985. The inverse relation between fish consumption and 20-year mortality from coronary heart disease. N. Engl. J. Med. 312:1205-1209.

4. Leaf, A., and P. C. Weber. 1988. Cardiovascular effects of n-3 fatty acids. $N$. Engl. J. Med. 318:549-557.

5. Harris, W. S. 1989. Fish oils and plasma lipid and lipoprotein metabolism in humans: a critical review. J. Lipid Res. 30:785-807.

6. Illingworth, D. R., W. S. Harris, and W. E. Connor, 1984. Inhibition of low density lipoprotein synthesis by dietary omega- 3 fatty acids in humans. Arteriosclerosis. 4:270-275.

7. Harris, W. S., W. E. Connor, S. B. Inkeles, and D. R. Illingworth. 1984 Omega-3 fatty acids prevent carbohydrate-induced hypertriglyceridemia. Metabolism. 33:1016-1019.

8. Harris, W. S., W. E. Connor, and M. P. McMurry. 1983. The comparative reductions of the plasma lipids and lipoproteins by dietary polyunsaturated fats: salmon oil versus vegetable oils. Metabolism. 32:179-184.

9. von Lossonczy, T. O., A. Ruiter, H. C. Bronsgeest-Schoute, C. M. van Gent, and R. J. J. Hermuss. 1978. The effect of a fish diet on serum lipids in healthy human subjects. Am. J. Clin. Nutr. 31:1340-1346.

10. Balasubramaniam, S., L. A. Simons, S. Chang, and J. B. Hickie. 1985. Reduction in plasma cholesterol and increase in biliary cholesterol by a diet rich in n-3 fatty acids in the rat. J. Lipid Res. 26:684-689.

11. Roach, P. D., A. M. Kambouris, R. P. Trimble, D. L. Topping, and P. J. Nestel. 1987. The effects of dietary fish oil on hepatic high density and low density lipoprotein receptor activities in the rat. FEBS (Fed. Eur. Biochem. Soc.) Lett. 222:159-162.

12. Ventura, M. A., L. A. Woollett, and D. K. Spady. 1989. Dietary fish oil stimulates hepatic low density lipoprotein transport in the rat. J. Clin. Invest. 84:528-537.

13. Dietschy, J. M. 1984. Regulation of cholesterol metabolism in man and in other species. Klin. Wochenschr. 62:338-345.

14. Packard, C. J., and J. Shepherd. 1982. The hepatobiliary axis and lipoprotein metabolism: effects of bile acid sequestrants and ileal bypass surgery. J. Lipid Res. 23:1081-1098.

15. Spanjer, H. H., M. van Galen, F. H. Roerdink, J. Regts, and G. L. Scherphof. 1986. Intrahepatic distribution of small unilamellar liposomes as a function of liposomal lipid composition. Biochim. Biophys. Acta. 863:224-230.

16. Scherphof, G., H. H. Spanjer, J. T. P. Derksen, F. Kuipers, R. J. Vonk, T Daemen, and F. Roerdink. 1987. Delivery of liposome-associated drugs to liver cells. Biochem. Soc. Trans. 15:345-348.

17. Kuipers, F., H. H. Spanjer, R. Havinga, G. L. Scherphof, and R. J. Vonk 1986. Lipoproteins and liposomes as in vivo cholesterol vehicles in the rat: preferential use of cholesterol carried by small unilamellar liposomes for the formation of muricholic acids. Biochim. Biophys. Acta. 876:559-566.

18. Spanjer, H. H., and G. L. Scherphof. 1983. Targeting of lactosyl-ceramide-containing liposomes to hepatocytes in vivo. Biochim. Biophys. Acta. 734:40-47.

19. Spanjer, H. H., H. Morselt, and G. L. Scherphof. 1984. Lactosylceramideinduced stimulation of liposome uptake by Kupffers cells in vivo. Biochim. Biophys. Acta. 774:49-55.

20. Beynen, A. C., C. E. West, L. F. M. Van Zutphen, and M. B. Katan. 1986. Relation between the responses of serum cholesterol to dietary cholesterol and to the type of dietary fat in random-bred rabbits. Nutr. Rep. Int. 33:71-78.

21. Kuipers, F., R. Havinga, H. Bosschieter, G. P. Toorop, F. R. Hindriks, and R. J. Vonk. 1985. Enterohepatic circulation in the rat. Gastroenterology. 88:403-411.

22. Steffens, A. B. 1969. A method for frequent sampling of blood and continuous infusion of fluids in the rat without disturbing the animal. Physiol. \& Behav. 4:833-836. 
23. Princen, H. M. G., C. M. G. Huijsmans, F. Kuipers, R. J. Vonk, and H. J. M. Kempen. 1986. Ketoconazole blocks bile acid synthesis in hepatocyte monolayer cultures and in vivo in rat by inhibiting cholesterol $7 \alpha$-hydroxylase. $J$. Clin. Invest. 78:1064-1071.

24. Princen, H. M. G., P. Meijer, J. Kwekkeboom, and H. J. M. Kempen. 1988. Assay of cholesterol $7 \alpha$-hydroxylase activity in rat hepatocytes in primary monolayer culture. Anal. Biochem. 171:158-165.

25. Philipp, B. W., and D. J. Shapiro. 1979. Improved methods for the assay and activation of 3-hydroxy-3-methylglutaryl coenzyme A reductase. J. Lipid Res. 20:588-593.

26. Billheimer, J. T., D. Tavani, and W. R. Nes. 1981. Effect of a dispersion of cholesterol in Triton WR-1339 on Acyl CoA: cholesterol acyltransferase in rat liver microsomes. Anal. Biochem. 111:331-335.

27. Meier, P. J., E. S. Sztul, A. Reuben, and J. L. Boyer. 1984. Structural and functional polarity of canalicular and basolateral plasma membrane vesicles isolated in high yield from rat liver. J. Cell Biol. 98:991-1000.

28. Scharschmidt, B. F., E. B. Keeffe, N. M. Blankenship, and R. K. Ockner. 1979. Validation of a recording spectrophotometric method for measurement of membrane-associated Mg- and NaK-ATPase activity. J. Lab. Clin. Med. 93:790799.

29. Goldbarg, J. A., and A. M. Rutenberg. 1958. The colorimetric determination of leucine aminopeptidase in urine and serum of normal subjects and patients with cancer and other diseases. Cancer (Phila.). 11:283-291.

30. Keeffe, E. B., B. F. Scharschmidt, N. M. Blankenship, and R. K. Ockner. 1979. Studies of relationships among bile flow, liver plasma membrane NaK-AT Pase, and membrane microviscosity in the rat. J. Clin. Invest. 64:1590-1598.

31. De Duve, C., B. C. Pressman, R. Gianetto, R. Wattiaux, and F. Appelmans. 1955. Tissue fractionation studies. 6. Intracellular distribution patterns of enzymes in rat-liver tissue. Biochem. J. 60:604-617.

32. Sottocasa, G. L., B. Kuylenstierna, L. Ernster, and A. Bergstrand. 1967. An electron-transport system associated with the outer membrane of liver mitochondria. A biochemical and morphological study. J. Cell Biol. 32:415-438.

33. Rothstein, T. L., and J. J. Blum. 1973. Lysosomal physiology in Tetrahymena. I. Effect of glucose, acetate, pyruvate, and carmine on intracellular conten and extracellular release of three acid hydrolases. J. Cell Biol. 57:630-641.

34. Wolters, H., and A. W. T. Konings. 1984. Radiosensitivity of normal and polyunsaturated fatty acid supplemented fibroblasts after depletion of glutathione. Int J Radiat. Biol 46:161-168.

35. Princen, H. M. G., and P. Meijer. 1988. Hydroxylation, conjugation and sulfation of bile acids in primary monolayer cultures of rat hepatocytes. Biochem. Biophys. Res. Commun. 154:1114-1121.

36. Bligh, E. G., and W. J. Dyer. 1959. A rapid method of total lipid extraction and purification. Can. J. Biochem. Biophys. 37:911-917.

37. Gamble, W., M. Vaughan, M. S. Kruth, and J. Avigan. 1978. Procedure for determination of free and total cholesterol in micro- and nanogram amounts suitable for studies with cultured cells. J. Lipid Res. 19:1068-1071.

38. Böttcher, C. F. J., C. M. van Gent, and C. Pries. 1961. A rapid and sensitive sub-micro-phosphorus determination. Anal. Chim. Acta. 24:203-204.

39. Sullivan, D. R., Z. Kruijswijk, C. E. West, M. Kohlmeier, and M. B. Katan. 1985. Determination of serum triglycerides by an accurate enzymatic method not affected by free glycerol. Clin. Chem. 31:1227-1228.

40. Lowry, O. H., N. J. Rosebrough, A. L. Farr, and R. J. Randall. 1951. Protein measurement with the Folin phenol reagent. J. Biol. Chem. 193:265-275.

41. Smit, M. J., A. M. Temmerman, R. Havinga, F. Kuipers, and R. J. Vonk. 1990. Short- and long-term effects of biliary drainage on hepatic cholesterol metabolism in the rat. Biochem. J. 269:781-788.

42. Berthelot, P., S. Erlinger, D. Dhumeaux, and A.-M. Preaux. 1970. Mechanism of phenobarbital-induced hypercholeresis in the rat. Am. J. Physiol. 219:809-813.

43. Lawson, A. M., and K. D. R. Setchell. 1988. Mass spectrometry of bile acids. In The Bile Acids. Chemistry, Physiology and Metabolism. K. D. R. Setchell, D. Kritschevsky, and P. P. Nair, editors. Plenum Publishing Corp., New York and London, pp. 167-259.

44. Sander, T. A. B., D. R. Sullivan, J. Reeve, and G. R. Thompson. 1985. Triglyceride-lowering effect of marine polyunsaturates in patients with hypertriglyceridemia. Arteriosclerosis. 5:459-465.

45. Wong, S. H., P. J. Nestel, R. P. Trimble, G. B. Storer, R. J. Illman, and D. L. Topping. 1984. The adaptive effects of dietary fish and safflower oil on lipid and lipoprotein metabolism in perfused rat liver. Biochim. Biophys. Acta. 729:103-109.

46. Nestel, P. J., W. E. Connor, M. F. Reardon, S. Connor, S. Wong, and R. Boston. 1984. Suppression by diets rich in fish oil of very low density lipoprotein production in man. $J$. Clin. Invest. 74:82-89.

47. Rustan, A. C., J. O. Nossen, E. N. Christiansen, and C. A. Drevon. 1988. EPA reduces hepatic synthesis and secretion of triacylglycerol by decreasing the activity of acyl-coenzyme A:1,2-diacylglycerol acyltransferase. $J$. Lipid Res. 29:1417-1426
48. Nassar, B. A., Y. S. Huang, M. S. Manku, U. N. Das, N. Morse, and D. F. Horrobin. 1986. The influence of dietary manipulation with n-3 and n-6 fatty acids on liver and plasma phospholipid fatty acids in rats. Lipids. 21:652-656.

49. Nossen, J. O., A. C. Rustan, S. H. Gloppestad, S. Malbakken, and C. A. Drevon. 1986. Eicosapentaenoic acid inhibits synthesis and secretion of triacylglycerols by cultured rat hepatocytes. Biochim. Biophys. Acta. 879:56-65.

50. Marsh, J. B., D. L. Topping, and P. J. Nestel. 1987. Comparative effects of fish oil and carbohydrate on plasma lipids and hepatic activities of phosphatidate phosphorylase, diacylglycerol acyltransferase and neutral lipase activities in the rat. Biochim. Biophys. Acta. 922:239-243.

51. Yamazaki, R. K., T. Shen, and G. B. Schade. 1987. A diet rich in n-3 fatty acids increases peroxisomal beta-oxidation activity and lowers plasma triacylglycerols without inhibiting glutathione-dependent detoxification activities in the rat liver. Biochim. Biophys. Acta. 920:62-67.

52. Spady, D. K., E. F. Stange, L. E. Bilharz, and J. M. Dietschy. 1986. Bile acids regulate hepatic low density lipoprotein receptor activity in the hamster by altering cholesterol flux across the liver. Proc. Natl. Acad. Sci. USA. 83:19161920.

53. Junker, L. H., and R. A. Davis. 1989. Receptor-mediated uptake of low density lipoprotein stimulates bile acid synthesis by cultured rat hepatocytes. $J$. Lipid Res. 30:1933-1941.

54. Spady, D. K., S. D. Turley, and J. M. Dietschy. 1985. Rates of low density lipoprotein uptake and cholesterol synthesis are regulated independently in the liver. J. Lipid Res. 26:465-472.

55. Stange, E. F., J. Schreiber, and H. Ditschuneit. 1989. Role of primary and secondary bile acids as feedback inhibitors of bile acid synthesis in the rat in vivo. J. Clin. Invest. 84:173-180.

56. Hall, R., E. Kok, and N. B. Javitt. 1988. Bile acid synthesis: down-regulation by monohydroxy bile acids. FASEB (Fed. Am. Soc. Exp. Biol.) J. 2:152-156.

57. Bijleveld, C. M. A., R. J. Vonk, F. Kuipers, R. Havinga, R. Boverhof, B. J. Koopman, B. G. Wolthers, and J. Fernandes. 1989. Benign recurrent intrahepatic cholestasis; altered bile acid metabolism. Gastroenterology. 97:427-432.

58. Lillienau, J., J. Munoz, S. J. Langmire-Cook, and A. F. Hofmann. 1990. Negative feedback regulation of the ileal bile acid transport system: the second site of regulation of the EHC. Abstract. XI International Bile Acid Meeting, Freiburg, FRG. p. 30.

59. Björkhem, I. 1985. Mechanism of bile acid biosynthesis in mammalian liver. In New Comprehensive Biochemistry. Vol. 12. Sterols and Bile Acids. H. Danielsson and J. Sjövall, editors. Elsevier Science Publishers B. V., Amsterdam. pp. 231-272.

60. Björkhem, I., M. Eriksson, and K. Einarsson. 1983. Evidence for a lack of regulatory importance of the $12 \alpha$-hydroxylase in formation of bile acids in man: $\mathrm{n}$ in vivo study. J. Lipid Res. 24:1451-1456.

61. Angelin, B., and L. A. Carlson. 1986. Bile acids and plasma high density lipoproteins: biliary lipid metabolism in fish eye disease. Eur. J. Clin. Invest. 16:157-162.

62. Danielsson, H., and J. Gustafsson. 1981. Biochemistry of bile acids in health and disease. In Pathobiology Annual. Vol. 11. H. L. Ioachim, editor. Raven Press, Ltd., New York. p. 259.

63. Björkhem, I., H. Danielsson, and J. Gustafsson. 1973. On the effect of thyroid hormone on 26-hydroxylation of $\mathrm{C}_{27}$-steroids in rat liver. FEBS (Fed. Eur. Biochem. Soc.) Lett. 31:20-22.

64. Stange, E. F., D. K. Spady, and J. M. Dietschy. 1985. Characterization of cholesterol precursor pools used for bile acid synthesis in the rat. In Enterohepatic Circulation of Bile Acids and Sterol Metabolism. G. Paumgartner, A. Stiehl, and W. Gerok, editors. MTP Press, Lancaster, UK. pp. 29-36.

65. Topping, D. L., R. J. Illman, P. D. Roach, R. P. Trimble, A. Kambouris, and P. J. Nestel. 1990. Modulation of the hypolipidemic effect of fish oils by dietary fiber in rats: studies with rice and wheat bran. J. Nutr. 120:325-330.

66. Kuipers, F., T. Dijkstra, R. Havinga, W. van Asselt, and R. J. Vonk. Acute effects of pentobarbital-anaesthesia on bile secretion. Biochem. Pharmacol. 34:1731-1736.

67. Ballarori, N., and A. T. Truong. 1989. Relation between biliary glutathione excretion and bile acid-independent bile flow. Am. J. Physiol. 256:G1-G7.

68. Erlinger, S. 1982. Does $\mathrm{Na}^{+}-\mathrm{K}^{+}$-ATPase have any role in bile secretion? Am. J. Physiol. 243:G243-G247.

69. Stenson, W. F., B. Seetharam, V. Talkad, W. Pickett, P. Dudeja, and T. A Brasitus. 1989. Effects of dietary fish oil supplementation on membrane fluidity and enzyme activity in rat small intestine. Biochem. J. 263:41-45.

70. Brasitus, T. A., R. Dahiya, P. K. Dudeja and B. M. Bissonnette 1988 Cholesterol modulates alkaline phosphatase activity of rat intestinal microvillus membranes. J. Biol. Chem. 263:8592-8597.

71. Ogawa, H., J. Mink, W. G. M. Hardison, and K. Miyai. 1990. Alkaline phosphatase activity in hepatic tissue and serum correlates with amount and type of bile acid load. Lab. Invest. 62:87-95. 